HEDL-SA-1911

CONF- $791058 \cdots 50$

\title{
BETA AND GAMMA DECAY HEAT EVALUATION FOR THE THERMAL FISSION OF ${ }^{235} \underline{U}$
}

GK Schenter

F. Schmittroth

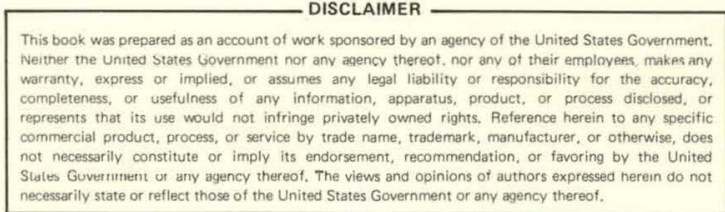

International Conference on

Nuclear Cross Sections for Technology

October 22-26, 1979 Knoxville, TN

\section{HARFORD ENGINEERING DEVELOPMENT LABORATORY}

Operated by Westinghouse Hanford Company, a subsidiary of

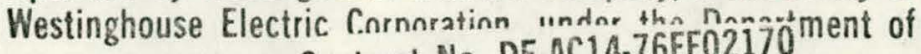

Energy Contract No. DE-AC14-76FF02

COPYRIGHI LICENSE NOTICE

By acceptance of this article, the Pubisher and or recipient acknowiedges the U.S.

Government's Iight to retain a nonexclusive, royalty-tree license in and to any copynght

covering this paper. 


\section{DISCLAIMER}

This report was prepared as an account of work sponsored by an agency of the United States Government. Neither the United States Government nor any agency Thereof, nor any of their employees, makes any warranty, express or implied, or assumes any legal liability or responsibility for the accuracy, completeness, or usefulness of any information, apparatus, product, or process disclosed, or represents that its use would not infringe privately owned rights. Reference herein to any specific commercial product, process, or service by trade name, trademark, manufacturer, or otherwise does not necessarily constitute or imply its endorsement, recommendation, or favoring by the United States Government or any agency thereof. The views and opinions of authors expressed herein do not necessarily state or reflect those of the United States Government or any agency thereof. 


\section{DISCLAIMER}

Portions of this document may be illegible in electronic image products. Images are produced from the best available original document. 
BETA AND GAMMA DECAY HEAT EVALUATION

FOR THE THERMAL FISSION OF $235 \mathrm{U}$

\author{
G. K. Schenter and F. Schmittroth \\ Hanford Engineering Development Laboratory \\ Richland, Washington 99352
}

Beta and gamma fission product decay heat curves are evaluated for the thermal fission of ${ }^{235} \mathrm{U}$. Experimental data that include beta, gamma, and total measurements are combined with summation calculations based on ENDF/B in a consistent evaluation. Least-squares methods are used that take proper account of data uncertainties and correlations.

[235 $\mathrm{U}$, fission-products, decay heat, evaluation]

\title{
Introduction
}

There has been an increased interest in fission-product decay heat in recent years, in part because of its importance in loss-of-coolant-accidents (LOCA). Although the need in LOCA is for the total decay heat, there are several reasons for studying the beta and gamma components separately. First, many experimental measurements include only one component or the other. Also, many reactor applications actually depend on the separate components. The individual components also provide a much more severe test of the nuclear data libraries such as ENDF/B that are used in summation calculations to compute decay heat. The present study is devoted to an updated evaluation of the total decay heat and its beta and gamma components for the thermal fission of ${ }^{235} \mathrm{U}$. A generalized least-squares approach is used that can properly account for important uncertainties and correlations in the data. Although numerous reviews and comparisons of decay heat experiments have been made [see Ref. (1) for a thorough and up-to-date review of decay heat], very few have attempted an objective evaluation that properly weights the various data. And except for a recent evaluation of the total, ${ }^{2}$ detailed covariance information has not been included.

\section{Method}

\section{Least-squares model equation}

In principle, the method is quite simple. One casts the problem into a least-squares format and solves the resulting problem. Techniques ${ }^{3,4}$ to keep the problem to a manageable size considerably complicate the situation but are not discussed in depth here. As a first step, we expand the time-multiplied beta decay-heat function $\operatorname{tf}_{\beta}(t)$ in a sum of finite element basis functions $\left\{\Delta_{j}(u)\right\}$ :

$$
t f_{\beta}(t)=\sum_{i} x_{B i} \Delta_{i}(u)
$$

where $u=\ln (t)$, and $t$ denotes cooling time. These bas is functions are trivially defined by first establishing a mesh of points $\left\{t_{j}\right\}$ on the cooling-time axis. The $i$-th basis function is then defined as a triangle of unit height whose vertex is at $u_{j}=\ln \left(t_{j}\right)$ and whose legs terminate at $u_{j-1}=\ln \left(t_{j-1}\right)$ and $u_{j+1}=\ln \left(t_{j+1}\right)$. This representation is discussed in detail elsewhere in this conference and is equivalent to representing $t f_{\beta}(t)$ as a piecewise linear and continuous function 
relative to $u=\ln (t)$. The number and spacing of the points $\left\{t_{j}\right\}$ can be chosen to ensure an adequate representation of $f_{\beta}(t)$. Clearly, Eq. (1) can also be used to represent the gamma decay heat $f_{Y}(t)$ where one replaces the expansion coefficients $\left\{X_{B i}\right\}$ by new coefficients $\left\{X_{\gamma j}\right\}$.

In Eq. (1), $f(t)$ represents the decay heat from a fission pulse $\left[f(t)\right.$ could denote beta, gamma, or total decay heat]. If a measurement $f_{m \alpha}$ of $f(t)$ at a time $t_{\alpha}$ is made, we have

$$
f_{m \alpha}=\sum_{i} A_{\alpha i}^{p} x_{i},
$$

where

$$
A_{\alpha i}^{P}=t_{\alpha}^{-1} \Delta_{i}\left(t_{\alpha}\right)
$$

For a complete set of measurements $\left\{f_{m \alpha}\right\}$, Eq. (2) has the standard least-squares form whereby one uses the measurements $\left\{f_{m \alpha}\right\}$ to find the least-squares parameters $\left\{x_{j}\right\}$ that define $f(t)$.

Most decay heat measurements are integral measurements such as

$$
F(t, T)=\int_{t}^{t+T} f(t) d t
$$

for a finite irradiation time $T$. Assume that one has a set of integral measurements $\left\{F_{m \alpha}=F\left(t_{\alpha}, T_{\alpha}\right)\right\}$ measured for the respective times $\left\{\left(t_{\alpha}, T_{\alpha}\right)\right\}$. Substitution of Eq. (Y) into Eq. (4) yields

where

$$
F_{m \alpha}=\sum_{i} A_{\alpha i}^{f} x_{i},
$$

$$
A_{\alpha i}^{f}=\int_{t}^{t+T} t^{-1} \Delta_{j}\left[\ln \left(t^{-}\right)\right] d t^{-} .
$$

Once the set of matrix elements $\left\{A_{a i}^{f}\right\}$ are calculated, Eq. (5) is simply another least-squares model equation, and integral data can be included along with the pulse data in Eq. (2). Other types of integral measurements are treated similarly.

The present evaluation includes total measurements along with beta and gamma measurements. We do this by defining a single parameter vector $\vec{x}$ that is the union of the beta and gamma parameter vectors: 


$$
\vec{x}=\left(\vec{x}_{B}, \vec{x}_{\gamma}\right)=\left(x_{B_{1}}, x_{B_{2}}, \ldots, x_{\gamma_{1}}, \ldots\right)
$$

In this combined space, all decay heat measurements whether integral or pulse or whether total, beta, or gamma can be included in a single equation of the form -

$$
\vec{F}_{m}=A \vec{X}
$$

One simply computes the appropriate A-matrix. The dimensionality of $\vec{x}$ is $2 N$ where $N$ is the number of mesh points used to separately represent $f_{B}(t)$ and $f_{\gamma}(t)$. In our case $N=54$. The measurement vector $\bar{F}_{m}$ includes all measured data points for all data used plus values obtained from summation calculations. Its dimensionality is several hundred.

\section{Least-squares solution}

The least-squares algorithm is defined by the minimization of

$$
S_{r}^{2}=\left(\vec{F}_{m}-A \vec{x}\right) M_{f}^{-1}\left(\vec{F}_{m}-A \vec{x}\right)+\left(\vec{x}_{-} \vec{x}_{0}\right) t_{M_{0}^{-1}}\left(\vec{x}_{-} \vec{x}_{0}\right)
$$

The first term is the usual least-squares form whereby one seeks the leastsquares solution $A \vec{X}$ that best represents the data $\vec{F}_{m}$. The data covariance matrix $M_{f}$ gives a proper weighting to the data and includes both uncertainties and correlations. The segond term allows the specification of prior information for the parameter vector $\vec{x}$. It could represent the results from other experiments or calculations; however, here the only significant prior information that is used is that the decay heat curves must be smooth. This smoothness is assured by assigning prior values $\left\{x_{0 j}\right\}$ that follow a smooth curve and that are very strongly correlated. Very large uncertainties are specified so that the magnitude of these values does not influence the results.

\section{Covariance parameterization}

In order to simplify the construction of the data covariance matrices, the following parameterization was used

$$
\frac{\left(M_{f}\right)_{i j}}{F_{m i}^{\prime} F_{m j}}=c^{2}+\cdot r_{i} \dot{r}_{j} \rho_{i j}
$$

where

$$
\rho_{i j}=\delta_{i j}(1-\theta)+\theta \exp \left[-\frac{\ln ^{2}\left(E_{i} / E_{j}\right)}{\ln ^{2}(\gamma)}\right]
$$


Each parameter has a simple physical interpretation. A fractional normalization uncertainty (complete correlation) is given by $C$. Any additional uncertainty at the $i$-th data point is given by $r_{j}$. The uncertainties $r_{j}$ are associated with a short-range correlation where $\theta$ gives the strength and $\gamma$ specifies the range of the correlation.

\section{$\underline{\text { Data }}$}

A brief summary of the data used in the evaluation is given in Table I. The total normalization uncertainty $C$ in column 9 is not quite as indicated. Several experiments included multiple irradiations. In these cases, part of the uncertainty in $C$ was taken as correlated over all values and part was taken as correlated only for data points belonging to a particular irradiation.

The use of calculated values based on ENDF/B and which appear as four separate entries in Table I needs to be clarified. The only case in which realistic uncertainties were assigned to the calculated values is for the total decay heat. In the remaining cases, the sole purpose of the ENDF/B based values was to provide a smoothing constraint as discussed above. The need for three additional calculations is beyond the scope of the present discussion. Constraining calculated values with small uncertainties were not included as separate beta and gamma components because it.was felt that only the total calculation was reliable enough to be treated as "measured" data.

\section{Results}

The results of the least-squares analysis are given in Table II for cooling times up to $10^{6} \mathrm{~s}$. The final uncertainties are calculated in the least-squares analysis and reflect a propagation of the data uncertainties and correlations given in Table I. These uncertainties therefore do not reflect any undetected systematic errors in the input data. However simple statistical checks were made and, in some cases, quoted experimental uncertainties were increased to ensure that the data were not statistically inconsistent. All uncertainties are quoted at one standard deviation $(1 \sigma)$.

The series of graphs in Figs. 1, 2, and 3 show the fractional deviation of the values in each input data from the nominal least-squares values. Note that these comparisons are not for unfolded or otherwise transformed data. For each plot, the comparison is with nominal least-squares values that are calculated for the specific irradiation times peculiar to each data set.

To illustrate the utility of these evaluations, we compare beta and gamma curves calculated from ENDF/B-IV for a pulse irradiation with the evaluated values. Fig. 4 shows that the ENDF/B-IV values show significant deviations that indicate inadequate nuclear data.

In conclusion we wish to note that the present evaluation is in reasonable agreement with the results of a recent evaluation of the total decay heat in support of a new ANS standard. Deviations average about 1\% for the pulse curve and are substantially less for longer irradiations. 


\section{References}

1. V. E. Schrock, Progress in Nucl. Energy, 3, 125 (1979).

2. F. Schmittroth and R. E. Schenter, Nucl. Sci. Eng., 69, 389 (1979).

3. F. Schmittroth, "A Method for Data Evaluation with Lognormal Distributions" (to be published in Nuc. Sci. Eng.).

4. F. Schmittroth, "FERRET Data Analys is Code", HEDL-TME 79-40, Hanford Engineering Development Laboratory (Sept. 1979):

5. J. K. Dickens, J. F. Emery, T. A. Love, J. W. McConnel1, K. J. Northcutt, R. W. Peelle, and H. Weaver, "Fission-Product Energy Release for Times Following Thermal-Neutron Fission of $235 \mathrm{U}$ Between 2 and 14,000 Seconds", ORNL/NUREG-14, Oak Ridge National Laboratory, (Oct. 1977).

6. S. J. Friesenhahn, N. A. Lurie, N. C. Rogers, and N. Vagelatos, "235U Fission Product Decay Heat From 1 to $10^{5}$ Seconds", EPRI NP-180, Electric Power Research Institute (Feb. 1976).

7. B. Alam and J. Scobie, Ann. of Nuc]. Sci. and Eng., 1, 537, (1974).

8. N. Tsoulfanides, B. W. Wehring, and M. E. Wyman, Nucl. Sci. and Eng., 43, 42 (1970).

9. A. McNair, F. J. Bannister, R. L. G. Keith and H. W. Wilson, J. Nucl. Energy, 23, 73, (1968).

10. T. D. MacMahon, R. Wellum and H. W. Wilson, J. Nucl. Energy, 24, 493 (1970).

11. Evaluated Nuclear Data File (ENDF/B-IV) available from, and maintained by, the National Nuclear Data Center at Brookhaven National Laboratory, Upton, New York; see also, T. R. England and R. E. Schenter, "ENDF/B-IV FissionProduct Files: Summary of Major Nuclide Data", LA-6116-MS(ENDF-233), Los Alamos Scientific Laboratory (Oct. 1975).

12. E. T. Jurney, P. J. Bendt, and T. R. England, "Fission Product Gamma Spectra", LA-7620-MS, Los Alamos Scientific Laboratory (Jan. 1979).

13. P. I. Johansson and G. Nilsson, "Measurement of Decay Energy Released in Thermal Fission of ${ }^{235} \mathrm{UI}^{\prime}$, AES-16, Aktiebolaget Atomenergi, Nykoping, Sweden, (Marc h 1977).

14. L. R. Bunney and D. Sam, Nucl. Sci. Engng, 39, 81 (1969).

15. P. C. Fisher and L. B. Eng.le, Phys. Rev., 134, B796 (1964).

16. J. L. Yarne 11 and P. J. Bendt, "Decay Heat from Products of $235 \mathrm{U}$ Thermal Fission by Fast Response Boil-Off Calorimetry", LA-NUREG-6713, Los ATamos Scientific Laboratory (Jan. 1977).

17. M. Lott, G. Lhianbet, F. Dufreche, and R. deTourrei1, J. Nucl. Energy, 27 597 (1973). 
TABLE 1

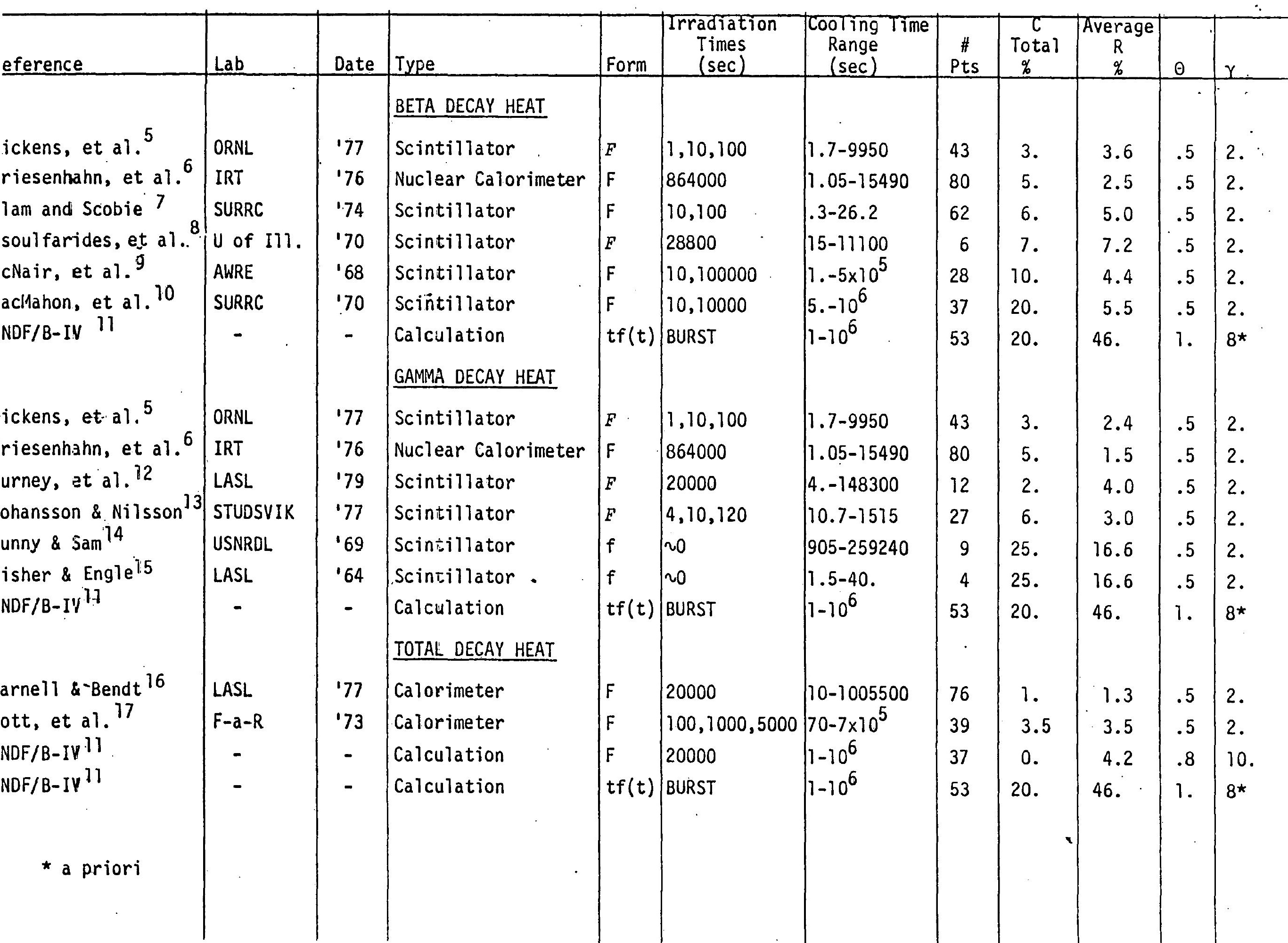




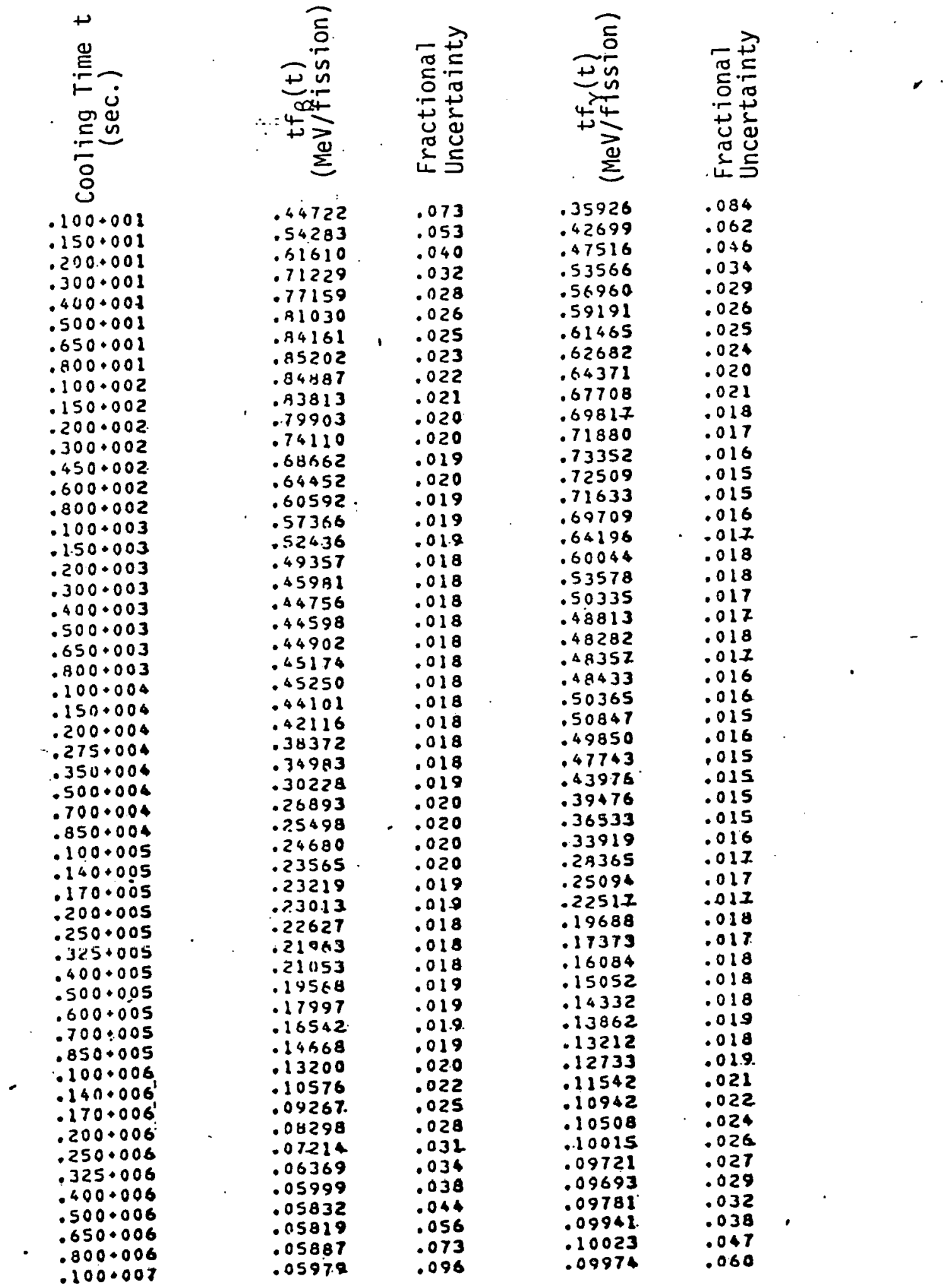


Figure 1

EVALUATED BETA DECAY HEAT
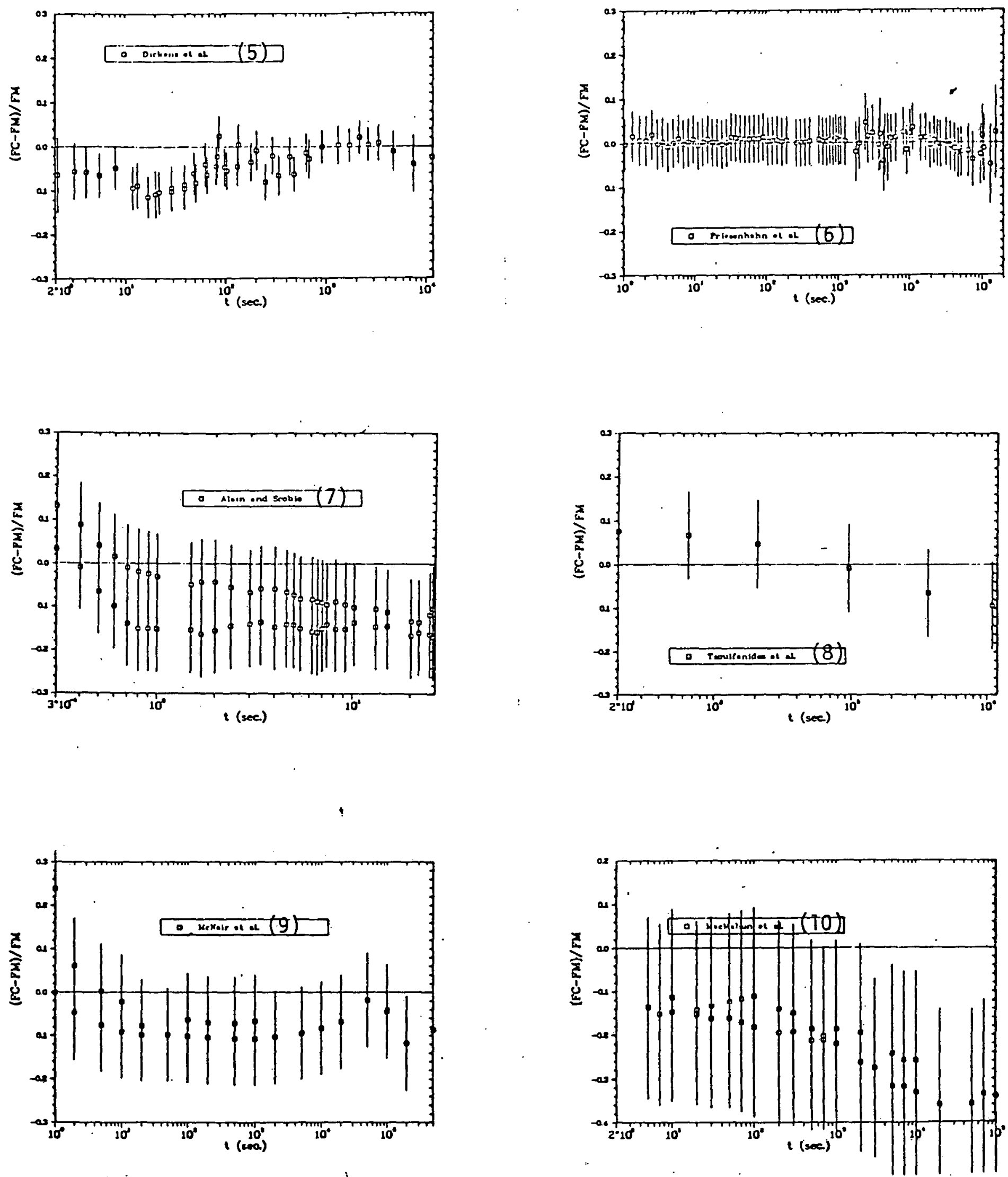
Figure 2

\section{EVALUATED GAMMA DECAY HEAT}
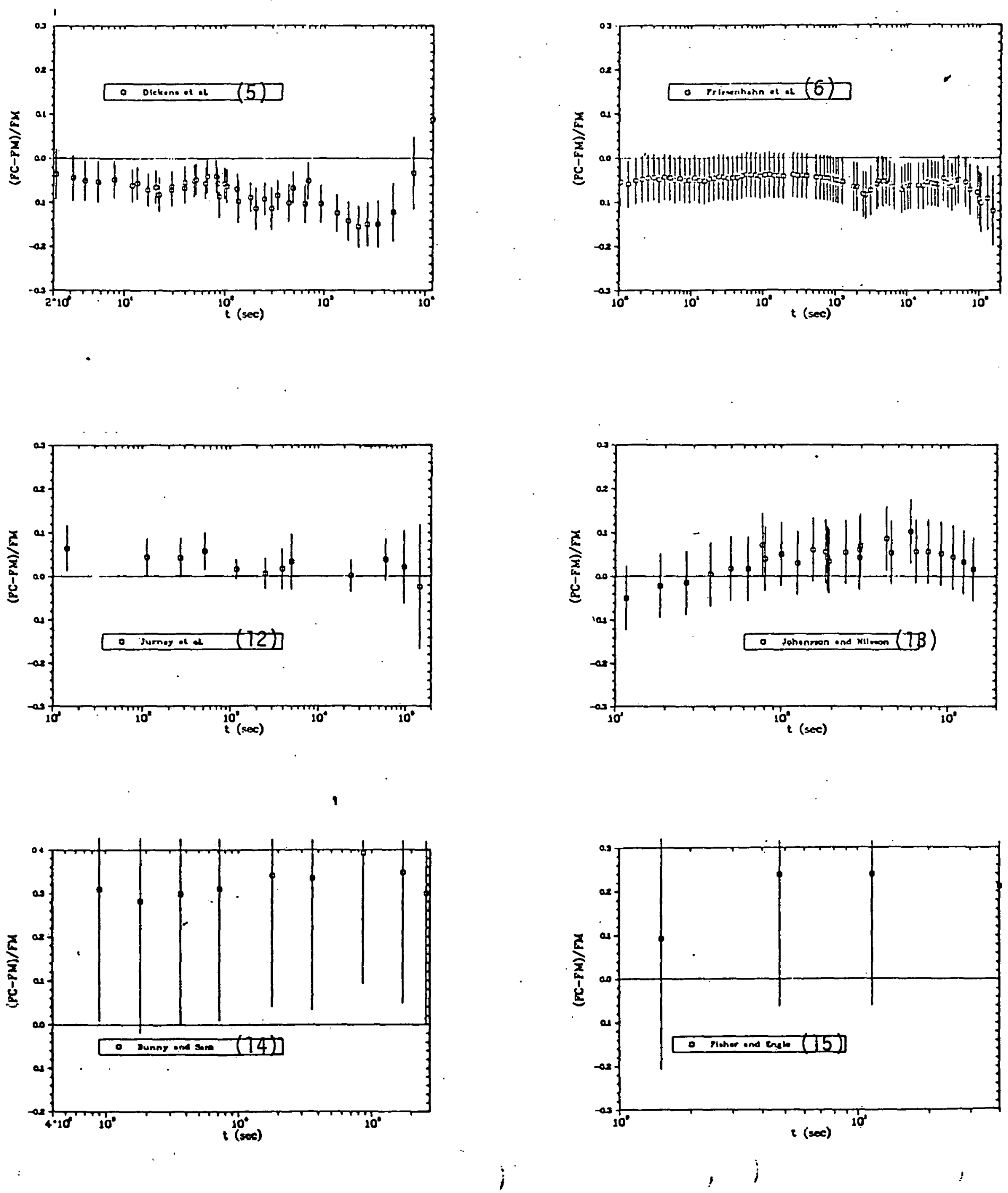
EVALUATED TOTAL DECAY-HEAT
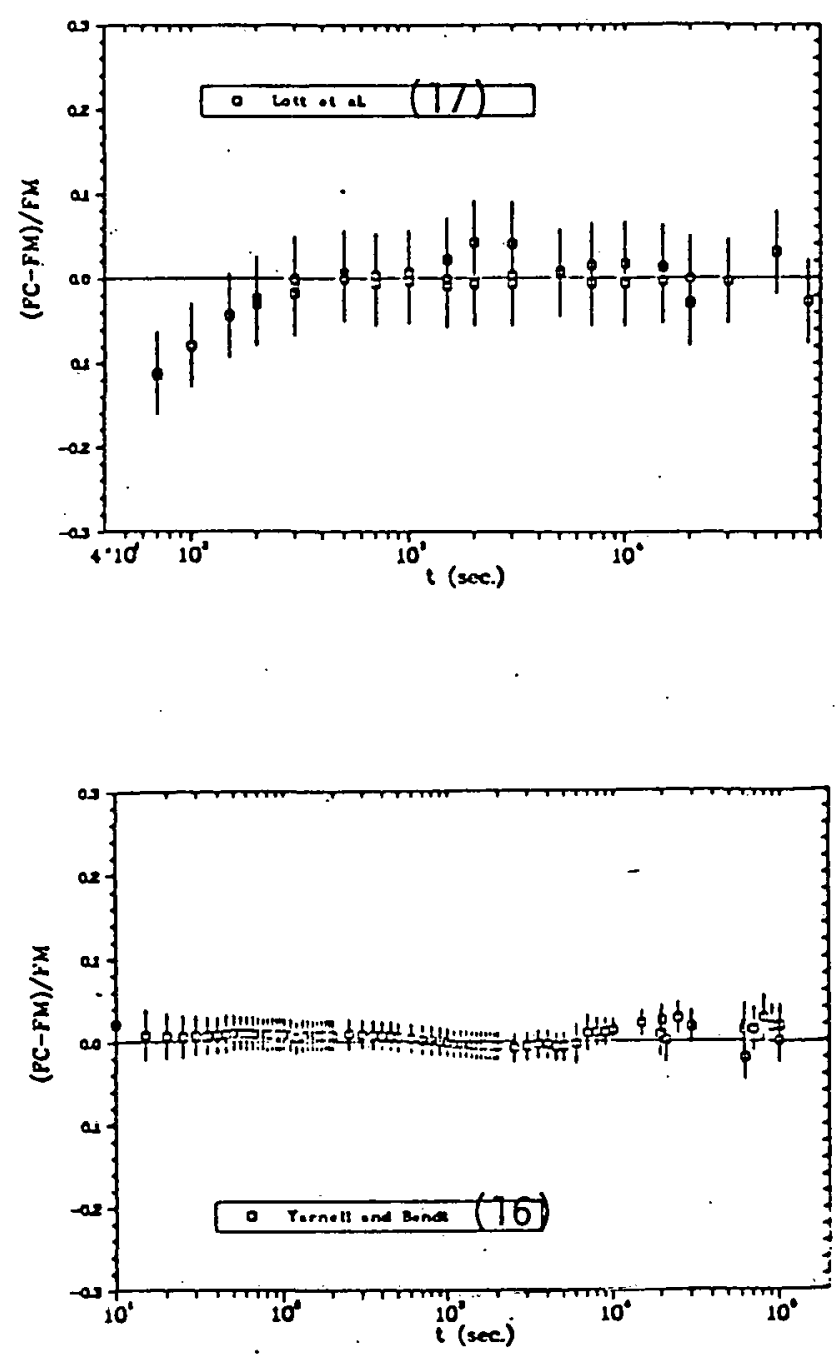

I

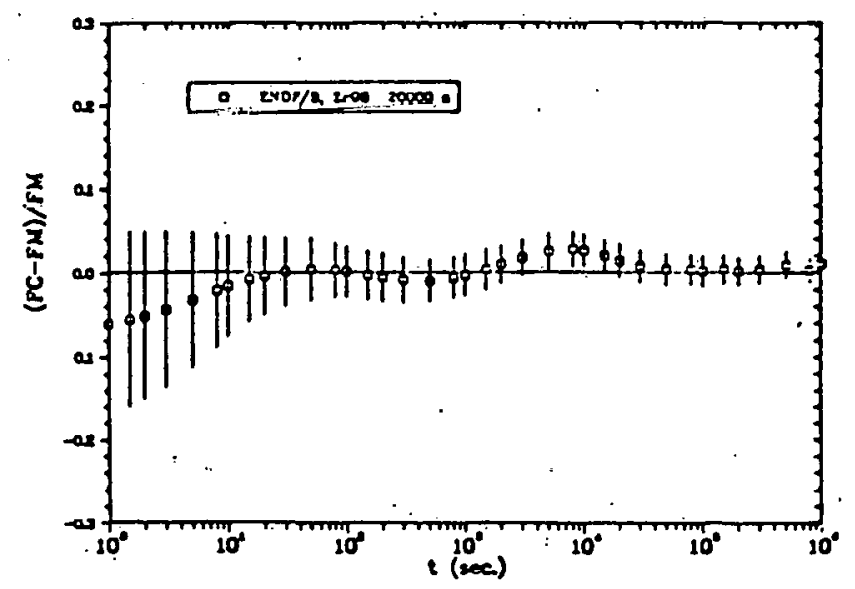




\section{Figure 4}
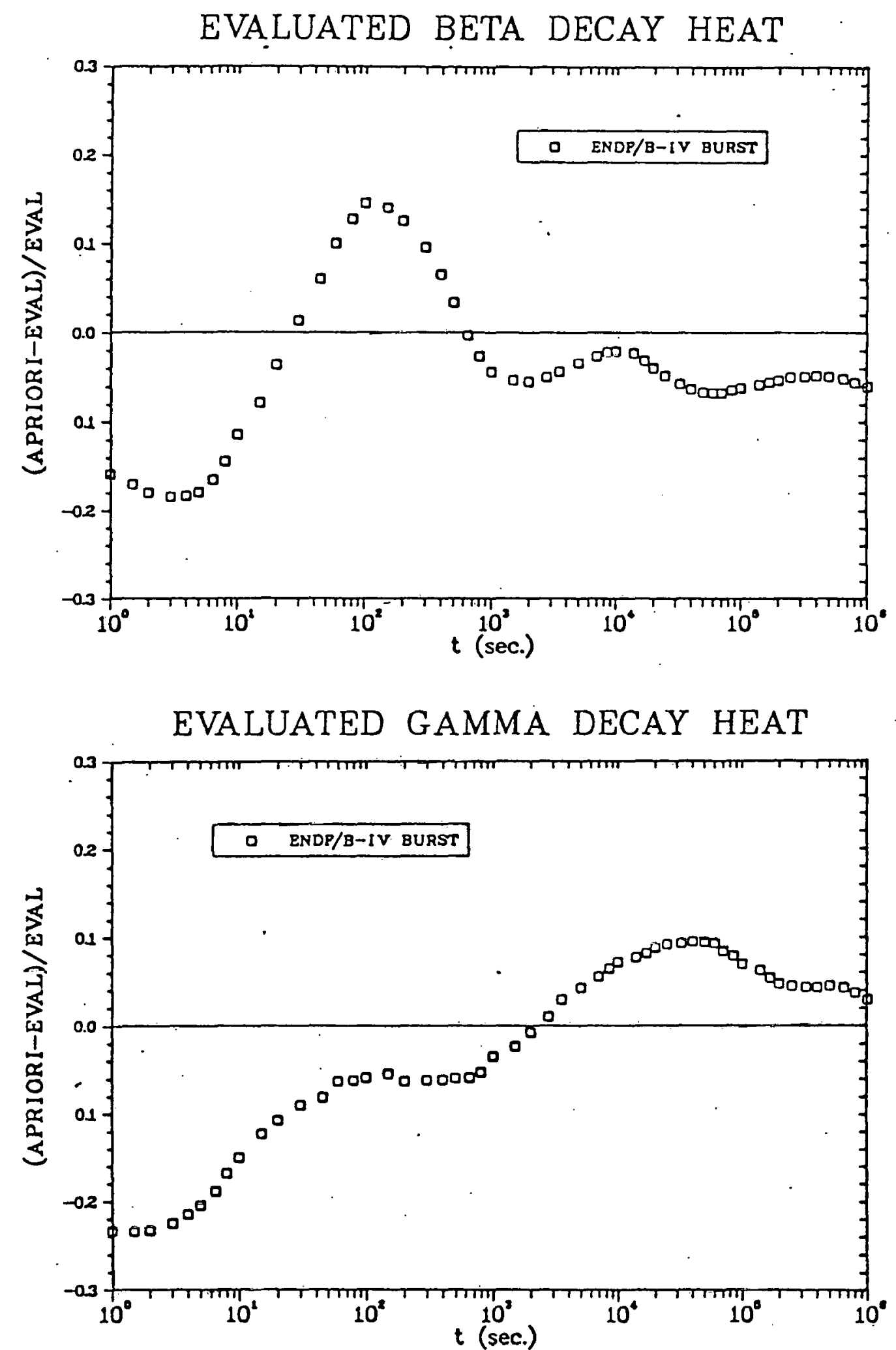